\title{
A Reply to Camilla Pickles' "Pregnancy Law in South Africa: Between Reproductive Autonomy and Foetal Interests"
}

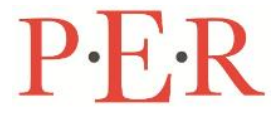

Pioneer in peer-reviewed, open access online law publications

\section{Author}

Shaun de Freitas

\section{Affiliation}

University of Free State

Email

\section{defreitas@ufs.ac.za}

Date Submission

30 April 2020

Date Revised

24 November 2021

Date Accepted

24 November 2021

Date published

14 January 2022

Editor Prof W Erlank

How to cite this article

De Freitas S "A Reply to Camilla Pickles' Pregnancy Law in South Africa: Between Reproductive

Autonomy and Foetal Interests" PER / PELJ 2022(25) - DOI

http://dx.doi.org/10.17159/17273781/2022/v25i0a8273

\section{Copyright}

DOI

http://dx.doi.org/10.17159/17273781/2022/v25i0a8273

\begin{abstract}
Camilla Pickles' Pregnancy Law in South Africa: Between Reproductive Autonomy and Foetal Interests (Pregnancy Law) aims at providing a less adversarial angle related to the pregnant woman and the unborn within her by moving away from viewing the pregnant woman as a single entity (including the unborn within her) as well as from viewing the pregnant woman and the unborn within her as two separate entities of distinctive value and with separate needs. This applies to four categories addressed by Pregnancy Law, namely foetal personhood, violence against pregnant women that terminates pregnancies, substance abuse during pregnancy, and the termination of pregnancy especially in the South African context. Pregnancy Law positions its argument on a relational model that emphasises the context of pregnancy as signifying a connection between the pregnant woman (with rights) and the unborn (with interests) inside her, the unborn being entirely dependent on the pregnant woman's body. This, in turn, is blended with what is referred to as a not-one/not-two approach. Bearing this in mind, Pregnancy Law claims to provide a compromise, a middle ground and a third approach regarding what is perceived to be the extremes of the single-entity and separate-entities approaches. Bearing this in mind, this article critically appraises Pregnancy Law's claims as alluded to above with a specific focus on the status of the unborn against the background of abortion (which in turn has implications for matters related to foetal personhood, violence against pregnant women that terminates pregnancies, and substance abuse during pregnancy).
\end{abstract}

\section{Keywords}

Abortion; right to life; reproductive rights; termination of pregnancy; pro-choice; pro-life. 


\section{Introduction}

The question as to when human life commences, as well as whether it should be protected or not, has attracted diverse views from philosophers, theologians and jurists, amongst others. This relates especially to what is today popularly referred to as abortion or the termination of pregnancy. It can be argued that a new era in the history of abortion began nearly half a century ago in Roe $v$ Wade ${ }^{1}(R o e)$ and Doe $v$ Bolton $^{2}(D o e)^{3}$ in that, for all practical purposes, abortion on demand suddenly became a matter of constitutional right almost everywhere in America. ${ }^{4}$ The gist of the Roe and the Doe rulings in the US context is that any pregnant woman, especially during the first two trimesters, ${ }^{5}$ may have an abortion for virtually any reason, provided that it is performed by a licensed physician. ${ }^{6}$ Since Roe, many countries have done away with a general prohibition of abortion. Substantive scholarly criticism has been levelled at Roe. ${ }^{7}$ Horan and Balch comment (albeit approximately thirty years ago) that in the history of American constitutional jurisprudence, Roe was one of the few Supreme Court decisions that have come to be recognised as so faulty and with such damaging social consequences that history has labelled them not only as controversial or erroneous but also as watersheds of ignominy. ${ }^{8}$ Especially

Shaun de Freitas. B Proc LLB LLM LLD. Professor, Faculty of Law, University of the Free State, South Africa. Adjunct Professor, School of Law, University of Notre Dame Australia (Sydney campus). Email: defreitas@ufs.ac.za. ORCiD: https://orcid.org/0000-0003-0236-0109.

Roe $v$ Wade 410 US 113 (1973).

Doe $v$ Bolton 410 US 179 (1973).

George "State Legislatures Versus the Supreme Court" 3. Eleven days before the Roe $v$ Wade judgment, in Doe $v$ Bolton the Supreme Court defined health by asserting that an abortion can be performed "in the light of all factors - physical, emotional, psychological, familial, and the woman's age - relevant to the well-being of the patient". All these factors may relate to the concept of health. Consequently, an abortion, even when the unborn is seven, eight, or nine months old (calculated from conception), can be performed for virtually any reason, including the mother's emotional stress caused by her pregnancy. See Beckwith and Geisler Matters of Life and Death 49.

$4 \quad$ Frankowski "United States of America" 23. Also see Bork Tempting of America 337.

5 For the purposes of this article, the first trimester refers to the first three months of pregnancy, the second trimester refers to the next three months of pregnancy whilst the third trimester represents the last three months of pregnancy.

$6 \quad$ Beckwith and Geisler Matters of Life and Death 49, 50-53.

7 See, for example, Byrn 1973 Fordham L Rev 807-862; Buelow 1990 Temp L Rev 963-994; Ely 1973 Yale LJ 920-949; Haley 1974 Suffolk U L Rev 145-184; O'Meara 1974 Sup Ct Rev 337-360; Rice 1973 Boston Coll Int'l \& Comp L Rev 307-341; Smith 1983 Jurist 289-317; Steegmann 1987 Ind LJ 369-399; Witherspoon 1985 St Mary's LJ 29-77; Paulsen 2003 Notre Dame L Rev 995-1044. Horan and Balch "Roe $v$ Wade" 57-60. 
since Roe, there has been a profusion of highly layered and contrasting scholarship regarding the legalisation of abortion. ${ }^{9}$ All of this confirms the challenges and complexities related to abortion, which in turn attract curiosity and circumspection on reading the following comment by Camilla Pickles in her published work titled, Pregnancy Law in South Africa: Between Reproductive Autonomy and Foetal Interests ${ }^{10}$ (hereafter referred to as Pregnancy Law),

\begin{abstract}
This book is dedicated to developing sound legal concepts of pregnancy and the pregnancy relationship, and meaningful legal responses to pregnancyrelated issues. It does this by focusing on and dismantling the tension, or the potential for tension, between women's and girls' reproductive autonomy and foetal interests during pregnancy in four specific areas: foetal personhood, violence against pregnant women that terminate pregnancies, substance abuse during pregnancy and termination of pregnancy. ${ }^{11}$
\end{abstract}

In reading Pregnancy Law it became clear that an appraisal was necessitated due to the claims it makes that it provides, amongst other things, a compromise, a middle ground, a third approach as well as sensitivity, and suggests that all of these claims are to be understood in the context of what Pickles refers to as the extreme approaches of the singleentity and separate-entities approaches. There has been a relatively fair amount of scholarship demonstrative of the existence of contrasting views on the topic in South Africa. ${ }^{12}$ Pregnancy Law adds to such scholarship and boldly proclaims the introduction of a "new" approach in support of the primacy of the rights of the pregnant woman in South Africa, as understood against a proposed relational background which forms the essence of a view labelled as the "not-one/not-two" approach. ${ }^{13}$ Apart from summarising the main issues raised in Pregnancy Law, this article also critically focuses on selected foundational claims arising from the pages of Pregnancy Law related to the delivery of a so-called third approach as well as achieving a compromise, a middle ground and sensitivity against the background of (as alluded to earlier) what Pickles refers to as the extreme views related to the

$9 \quad$ For the South African context see for example, De Freitas 2005 JJS 118-145; Pillay Stell LR 230-238; Ngwena Acta Academica 32-68; Ngwena 2000 JJS 19; and Ngwena 2004 JLME 708.

10 Pickles Pregnancy Law.

11 Pickles Pregnancy Law 1-2 (emphasis added). Also see Pickles Pregnancy Law 289.

12 See fn 9 above.

13 Although Pickles Pregnancy Law addresses not only the issue of abortion per se but also other matters related to pregnancy such as prenatal substance abuse by the pregnant woman, violence that terminates the pregnancy, and the extension of legal personhood to the unborn, this appraisal pertinently focuses on Pregnancy Law's approach to abortion, which implies the said work's approach to what the unborn is to be viewed as and which in turn overlaps with the additional topics referred to. 
single-entity and the separate-entities approaches, among other matters. This is followed by some final remarks related to the relevance of Pregnancy Law for pregnant women in general.

\section{What does Pregnancy Law say?}

The South African legal system, according to Pickles, is "lacking an informed foundation from which to work, which includes the essential aspects of pregnancy, being the constitutive parts of a pregnancy (women and the unborn) and the context in which pregnancies exist". ${ }^{14}$ Pregnancy Law aims at answering the question as to whether "the value of connection may serve as the basis for addressing the tension between foetal interests and female reproductive autonomy, ultimately allowing for both interests and rights to co-exist?"15 According to Pickles, "(t)he tension being expressed here is not a tension between a woman and the unborn she carries, but a tension between two concepts ${ }^{16}$ as developed and structured in law". ${ }^{17}$ Pickles then directs this thinking to the need, in the South African context, to move away from viewing the pregnant woman as a single entity (together with her foetus) ${ }^{18}$ and from viewing a pregnant woman and her foetus as two separate entities". ${ }^{19}$

Pickles deals with three approaches to pregnancy, ${ }^{20}$ namely the singleentity approach, the separate-entities approach, and the not-one/not-two approach. $^{21}$ The single-entity approach views the foetus as wholly subsumed (embodied) in and dependent on the pregnant woman's body, and the unborn is understood to be something similar to an organ. ${ }^{22}$ According to the separate-entities approach, the foetus is understood to be

\footnotetext{
14 Pickles Pregnancy Law 289 (emphasis added).

15 Pickles Pregnancy Law 337. Which in turn forms part of "developing sound legal concepts of pregnancy and the pregnancy relationship" (Pickles Pregnancy Law 1 (emphasis added)). Also see Pickles Pregnancy Law 11.

16 Which denote the single-entity and the separate-entities approaches.

17 Pickles Pregnancy Law 319.

18 For the purposes of this article, references to the "unborn" denote that which is formed at fertilisation and which ends at birth.

19 Pickles Pregnancy Law 4 (emphasis added). And how this relates not only to the application of termination-of-pregnancy laws but also to the extension of legal status to the unborn, violence against pregnant women, and where women inflict harm on themselves during pregnancy (Pickles Pregnancy Law 4-5). Note here Pickles' use of "pregnancy" and not "the unborn", which is already indicative of prioritising the former over the latter.

$21 \quad$ Pickles Pregnancy Law 343.

22 Pickles Pregnancy Law 6.
} 
a person in law, ${ }^{23}$ and the woman and her foetus are viewed as separate individuals of distinctive value with separable needs ${ }^{24}$ - the unborn is understood to have an entirely different status and enforceable rights. ${ }^{25}$ The not-one/not-two approach, says Pickles, "is seen to rest between the two extremes of the single-entity and the separate-entities approaches to pregnancy, offering a middle ground". ${ }^{26}$ The not-one/not-two approach rejects the single-entity and the separate-entities approaches by focussing on the shared connection between a pregnant woman and the foetus for the duration of the pregnancy and consequently recommends a specified relational approach to pregnancy. ${ }^{27}$ Pregnancy constitutes a connection between a woman and the foetus whereby the foetus is fully dependent ${ }^{28}$ on the pregnant woman's body, and pregnancy takes place biologically in a woman's body, thereby necessitating that the foetus must be understood as wholly part of the body of the pregnant woman. ${ }^{29}$

Pregnancy Law hinges on Nedelsky's relational theory, which recognises that human beings are not purely independent by nature in that they are continuously involved in relationships. We rely on our social world to enable us to realise our core capacities such as love, reason, creativity and autonomy. ${ }^{30}$ Pickles observes that according to Nedelsky, the role of law and rights is, amongst others, to assist in determining the quality of such relationships. There is a constant need to be aware of the central role of relationships and evaluate which ones are destructive so that there can be a liberation from such destructive relationships and a transformation of those structures that gave rise to the destructive relationship. ${ }^{31}$ Nedelsky's focus regarding core values, says Pickles, is on autonomy, and autonomy is elected as being central to a woman's attempt to self-define her life. However, Nedelsky views the prevailing liberal understanding of autonomy as defective due to its overemphasis on independence. "Relational autonomy", on the other hand, allows for the recognition that we are not

\footnotetext{
$23 \quad$ Pickles Pregnancy Law 6.

$24 \quad$ Pickles Pregnancy Law 158.

25 Pickles Pregnancy Law 144.

26 Pickles Pregnancy Law 142. Pickles refers to this approach as "a female view of pregnancy". In this regard, Pickles relies on the scholarship of Seymour Childbirth and the Law.

$27 \quad$ Pickles Pregnancy Law 8.

$28 \quad$ "... it is not the fact that the unborn cannot relate or are in the process of development that denies them full status, but that they are 'embodied' and factually live off of another's body". Pickles Pregnancy Law 306. Pickles Pregnancy Law 83-84. Also see Pickles Pregnancy Law 87. Nedelsky Law's Relations cited in Pickles Pregnancy Law 291-292. Nedelsky Law's Relations cited in Pickles Pregnancy Law 292-293.
} 
formed by ourselves but by our social relations. ${ }^{32}$ According to Pickles, interdependence rather than independence is understood by Nedelsky to be a constant component of autonomy. ${ }^{33}$

Pickles further observes that "anyone in any form of hierarchical relationship requires protection from the imposition of power and if participants in a relationship feel helpless or degraded, something is amiss, especially if autonomy instils a sense of power to shape and direct one's life". ${ }^{34}$ Pickles explains that according to Nedelsky, a relational mode of thinking must be inclusive "and to be inclusive means that as human beings we are obligated to hold 'respectful and responsible relations' with 'other life-forms', because all life holds intrinsic worth". ${ }^{35}$ She adds that "Even though Nedelsky does not specifically address the position of the unborn, the unborn can be included here by interpreting 'other life-forms' (that Nedelsky refers to) widely". ${ }^{36}$ Nedelsky labels pregnancy as a relationship, and where such pregnancy is unwanted by the pregnant woman then, according to Nedelsky, no woman should be compelled into such a "nine-month" pregnancy. ${ }^{37}$

According to this relational model of a pregnancy relationship, "others cannot directly relate to the unborn without implicating the women who carry them. They are, in effect, relating to the pregnancy unit or relationship as constituted by both a woman and a foetus". ${ }^{38}$ Pertaining to this construction, the focus should be on optimal pregnancy progression and optimal pregnancy outcomes and how third parties can secure this in their interaction with pregnancies. ${ }^{39}$ This, therefore, slots in with what Pickles views the central question of Pregnancy Law to be, namely "(c)an the value of connection serve as the basis for addressing the tension between foetal interests and female reproductive autonomy, ultimately allowing for both interests and rights to co-exist?"40 Pregnancy Law answers this in the affirmative and with specific reference to the Choice on Termination of

\footnotetext{
32 Nedelsky Law's Relations and Nedelsky 1989 Yale J L \& Feminism cited in Pickles Pregnancy Law 293.

33 Nedelsky 1989 Yale J L \& Feminism cited in Pickles Pregnancy Law 293.

$34 \quad$ Nedelsky 1989 Yale J L \& Feminism cited in Pickles Pregnancy Law 294.

$35 \quad$ Nedelsky Law's Relations cited in Pickles Pregnancy Law 295.

$36 \quad$ Pickles Pregnancy Law 295.

$37 \quad$ Nedelsky 1993 CJLJ cited in Pickles Pregnancy Law 296-297.

$38 \quad$ Pickles Pregnancy Law 319.

$39 \quad$ Pickles Pregnancy Law 319.

$40 \quad$ Pickles Pregnancy Law 337 (emphasis added).
} 
Pregnancy Act (hereafter referred to as the Choice Act). ${ }^{41}$ Pickles is of the view that "the majority of South African scholars who have written on the topic" have done so under the erroneous view that the Choice Act applies the single-entity approach and that Pregnancy Law "is aimed at showing otherwise". 42

For Pickles' not-one/not-two approach to succeed, just as is the case for anyone taking a stance on abortion, some or other worth needs to be conferred upon the unborn, also bearing in mind the various stages of development of the unborn. To Pickles, human dignity and viability play a focal role in ascribing meaning and importance to the foetus during the third trimester, ${ }^{43}$ but Pickles also concedes that science cannot guide us on how to respond in law. ${ }^{44}$ Pregnancy Law argues for the pregnant woman to have free passage to terminate pregnancy during the first two trimesters, especially, whilst doing away with this free passage during the third trimester. However, as alluded to earlier, nowhere is it evident (or implied)

$41 \quad$ Choice on Termination of Pregnancy Act 92 of 1996 (hereafter the Choice Act). This Act permits abortion on request by a woman (1) during the first 12 weeks of gestation; (2) during the $13^{\text {th }}$ to $20^{\text {th }}$ week of gestation if the pregnancy would pose a risk of injury to the woman's physical or mental health, or if there exists a substantial risk that the foetus would suffer from a severe physical or mental abnormality, or if the pregnancy resulted from rape or incest or if the pregnancy will significantly affect the woman's socio-economic situation; (3) after the $20^{\text {th }}$ week of gestation if there is a risk of injury to the foetus or if there is severe foetal malformation. Irrespective of these stipulations, it remains very easy for a woman to have a legal abortion in the second trimester as well. In this regard, see Van Oosten 1999 SALJ 60-76. Also see fn 66 below.

42 Pickles Pregnancy Law 344. Pickles fully supports the Choice Act. Of interest here are substantive concerns brought to the fore by Van Oosten (quite a number of years ago) regarding the formulation of the Choice Act. See Van Oosten 1999 SALJ 6076. In the words of Van Oosten 1999 SALJ 76: "That the Choice on Termination of Pregnancy Act is hardly a model of legislative genius is abundantly clear. Behind its ideological façade, and political clichés, it consists of little more than the decriminalization of abortion, and that result could have been achieved in a fraction of the space occupied by the Act. For the rest, the Act bristles with lacunae, contradictions, inconsistencies and incomprehensibilities, and demonstrates a stunning ignorance of the basic principles of criminal law, an inexplicable ambivalence on the issue of abortion, and a surprising insensitivity to the meaning of words on the legislator's part. One can only hope that the current lack of concern for competent legal draftsmanship will be a short-lived reactionary phenomenon". Also of interest is that this article by Van Oosten is not included in Pregnancy Law.

43 This will be critically elaborated upon below.

44 Pickles Pregnancy Law 185. Can science truly be viewed as not assisting at times in directing us in how to respond in law? Does the judiciary or the legislature exclude itself from being directed by science regarding many of the challenges that they are confronted with in endeavouring to maintain justice and promote the public good? 
in Pregnancy Law that the unborn constitutes a human life (or a person) ${ }^{45}$ worthy of protection ${ }^{46}$ throughout the pregnancy (or even during a specific phase of pregnancy).

How does Pickles go about determining the worth of the unborn also bearing in mind the various stages of pregnancy or the biological development of the unborn? To Pickles, "human dignity" and "viability" play a seminal role in this regard, where foetal viability and interests "feed into, support, and are bolstered by the notions of human dignity, thus building from dignity up". 47 Human dignity is perceived as "the foundational informative principle that sets down the parameters and directs how we should conduct ourselves when dealing with prenatal life". 48 Pickles further observes that although Ackermann's writing on human worth in respect of the unborn lacks in detailed information, the human dignity of the unborn can be contextualised using the scholarship of Ronald Dworkin - "Ackermann highlights that the unborn are afforded dignity and Dworkin helps identify what factors limit the unborn's dignity". 49 Drawing on Dworkin as authority for limiting the unborn's

45 It needs to be emphasised that references in this article to a "human life (or person)"/"human (or person)"/"human being (or person)" being worthy of protection in relation to the unborn suggest the equation of "human life", "human", and "human being" with a "person", thus evoking the notion of being worthy of protection. This is said because there are those who are in support of abortion, irrespective of their acknowledgement that the unborn constitutes human life. Patrick Lee points to those scholars who support the view that "while what is killed in an abortion is a human being, it is not a person and therefore abortion is not morally wrong. Since bearers of rights are called 'persons,' the same position could be expressed this way: the right to life is not acquired until after birth". Lee Abortion and Unborn Human Life 8. It is important to note this, as there are scholars who are supportive of abortion based on their support of the free choice of the pregnant woman, although they acknowledge the equating of the unborn with human life. In this regard see Perry Toward a Theory of Human Rights 131-132.

$47 \quad$ Pickles Pregnancy Law 307.

$48 \quad$ Pickles Pregnancy Law 307. Also see Pickles Pregnancy Law 306.

$49 \quad$ Pickles Pregnancy Law 306. Also see Pickles Pregnancy Law 70-71, 307. Pickles makes her confusion known in observing Ackermann's referral to the "dignity rights" (emphasis by Pickles) of the conceptus whilst he (Ackermann) also argues that is not suggested by this that the pregnant woman "does not have rights which are to be weighed up against the dignity rights of the conceptus..." (Pickles Pregnancy Law 71). Pickles also points out that although Ackermann refers to "certain aspects of the protection of human dignity that pre-date birth (and survive death)", he provides no indication as to what these "certain aspects" are or may be - rather, Ackermann places this matter in the hands of the "interpreter of the Constitution" (Pickles Pregnancy Law 70). From this it is clear that Ackermann is vague as to the meaning to be ascribed to the unborn. 
dignity suggests adopting a view that does not recognise the unborn as constitutive of human life worthy of protection. ${ }^{50}$

Pickles believes that viability presents a "worthwhile explanation as to how much more than 'nothing' the foetus will be" and "the limiting effect of the embodied approach decreases as the foetus develops towards the 'clinical construction' of foetal viability". ${ }^{51}$ Notwithstanding, how much attention the unborn should receive is dependent not only on the "point of prenatal development" but also on "the context in which pregnant women find themselves". That is why, says Pickles, experiments with products of human reproduction ex utero, for example, may be permissible, but this is not to say that no legislative regulation is required. ${ }^{52}$ To Pickles, therefore, the unborn is characterised as constitutive of a relative dimension depending on the context in which "it" finds "itself", which in turn would determine its degree of importance and whether it may enjoy protection or not. Regarding viability, Pickles states that

\begin{abstract}
Viewing viability through the informative lens of dignity (human worth), it is proposed that this somewhat more advanced stage of prenatal development justifies increased consideration or protection than that of embryos. This is so because viable foetuses are developing stronger connections to their eventual birth and the developmental process moves from being a biologically significant event to also being a socially significant event. Foetal viability thus bolsters the foetus' stake in respect of securing special status. ${ }^{53}$
\end{abstract}

50 A reading of Dworkin's popular work on abortion (and euthanasia) namely, Life's Dominion (published in 1993), confirms this. Life's Dominion is not immune from substantive concerns and in this regard Bradley has provided a superb critique levelled at Life's Dominion. See Bradley 2014 Notre Dame L Rev 329-391. Bradley comments that: "Dworkin's main escape hatch, however, is his denial that the fetus is a person or, he sometimes says, a creature of any sort with a right not to be killed. Dworkin goes back and forth on the humanity of the unborn, consistently denies that the unborn are persons, says sometimes they are just 'creatures,' claims that whether the unborn are humans or persons or just plain creatures does not matter. Here we see Dworkin doing philosophy 'inside out.' It is not a pretty sight" (Bradley 2014 Notre Dame L Rev 375). Bradley adds that "Dworkin is more erratic when discussing fetal personhood in a strictly moral (nonlegal) setting. He generally concedes the moral component of the detached argument. That is, he agrees that the unborn embody the intrinsic value of human life. Then again, he sometimes denies it" (Bradley 2014 Notre Dame L Rev 376), and he says that "Dworkin is not, we are obliged to conclude, talking to pro-lifers at all. To whom is he talking? $\mathrm{He}$ writes for the moderately sophisticated pro-choice crowd" (Bradley 2014 Notre Dame L Rev 390).

51 Pickles Pregnancy Law 307-308.

$52 \quad$ Pickles Pregnancy Law 307.

53 Pickles Pregnancy Law 309. 
Note in the above how Pickles allows for the scientific or biological determination to be accompanied by other measures such as "stronger connections to their eventual birth" and "the development towards a socially significant event". As alluded to earlier, although Pickles acknowledges the relevance of science for the determination of foetal interests, ${ }^{54}$ she states that "[s]cience can tell us whether what is developing is human enough to accrue some form of value, but it cannot direct us on how to respond in law". 55 According to Pickles, those who argue for the protection of the unborn because of what science teaches us of the unborn should rather focus on eliminating those factors that fuel the demand for abortion services and instead look at the various contexts in which pregnancies exist. ${ }^{56}$ Note here Pickles' departure from the relevance of the meaning to be attached to the unborn by her emphasis on surrounding circumstances that may qualify abortions. That science is of some importance to Pickles is confirmed by her rejection of the single-entity approach because, amongst other things, it does not speak to scientific fact. ${ }^{57}$

Bearing the above in mind, Pickles makes a point of not placing too much emphasis on the scientific approach, except during the third trimester. It is therefore clear from the above that Pickles attaches some importance to the unborn during the third trimester in the context of what Pickles refers to as the termination of pregnancies. Pickles' understanding of the unborn in the period preceding the third trimester, as referred to earlier, differs considerably from her understanding of the unborn during the third trimester. Regarding the unborn during the third trimester, human dignity and viability play a seminal role, and this overlaps with the relevance of science. The same cannot be said of Pickles' view of the unborn during the first two trimesters.

Pregnancy Law "is not aimed at discovering new ways and means of developing opportunities to grant a foetus constitutional rights ...".58 Biologically speaking, says Pickles, pregnancy occurs in the woman's body, "which requires that the unborn be understood as part and parcel of the woman's body" 59 - "pregnancy is a woman's concern, more so than anyone

$54 \quad$ Also see Pickles Pregnancy Law 187 for Pickles' alignment of the Choice Act with the scientific significance of viability in the protection of the unborn.

55 Pickles Pregnancy Law 185.

$56 \quad$ Pickles Pregnancy Law 185.

$57 \quad$ Pickles Pregnancy Law 303.

$58 \quad$ Pickles Pregnancy Law 10-11.

59 Pickles Pregnancy Law 83-84. Pickles also refers to Catharine MacKinnon's description of the unborn as being "More than a body part but less than a person ..." (Pickles Pregnancy Law 142). According to Pickles, "The 'part and parcel' does not 
else's, because it is something that occurs within her".60 Against the background of the application of Nedelsky's relational theory, Pickles distinguishes between human beings and "other life-forms" (such as animals or otherwise) and adds that "Even though Nedelsky does not specifically address the position of the unborn, the unborn can be included here by interpreting 'other life-forms' widely".61 According to Pickles, prenatal life will continue to be valued, "but whether we can act on that value, and how we go about protecting it, must be determined in the context in which the unborn exist, being through women and their rights". ${ }^{6}$

Therefore, in summary, it is clear that Pregnancy Law aims to present a middle ground pertaining to what Pickles refers to as the extreme views of the single-entity and the separate-entities approaches. This middle ground alleviates the tension that exists between the single-entity and separateentities approaches. Pregnancy Law does this by stressing the importance of the relationship between the pregnant woman and the unborn inside her in the context of pregnancy - pregnancy signifies the value of the shared connection between the two (a unit), in which the unborn is fully dependent on the body of the pregnant woman. Inextricably woven into the idea of pregnancy permeating Pregnancy Law are attributes such as united needs, interconnectedness, reciprocity, mutuality and unique context. Furthermore,

mean that the unborn are mere organs of a woman's body, but indicates that it is a woman's body that ensures continued gestation and development. Consequently, any discussion about status prior to birth requires the recognition that the unborn be considered in relation to the contextual setting of pregnancy and women too" (Pickles Pregnancy Law 84). Therefore, "while prenatal development signifies a process of the most basic form of human development, it is the additional fact that this development takes place in women's bodies that concretises the grounds of limiting the status of the unborn. As long as the limiting element of embodiment persists, the foetus will lack full status" (Pickles Pregnancy Law 84-85).

$60 \quad$ Pickles Pregnancy Law 341 (emphasis added).

$61 \quad$ Pickles Pregnancy Law 295.

62 Pickles Pregnancy Law 153. Pickles attaches the rights to equality, dignity, life, freedom and security of the person, privacy and reproductive health care to reproductive rights. See Pickles Pregnancy Law 99-125 for an elaboration in this regard. Pickles states: "It is expressly noted that a woman's reproductive rights are not qualified in the Constitution for the benefit of a foetus. This is not to say that their reproductive rights cannot be limited in terms of $s 36$ of the Constitution, but that the law does not qualify the value of women's legal existence based on the presence of a pregnancy" (Pickles Pregnancy Law 126). Although Pickles does not deem the unborn to be worthy of being the bearer of rights (Pickles Pregnancy Law 1) she attaches value to the foetus, namely "foetal interests", which Pickles explains as meaning "the biological drive inherent in all things living for survival" (Pickles Pregnancy Law 1-2). According to Pickles, reproductive decisions must be understood to include decisions to continue with a pregnancy as well as lifestyle choices during pregnancy (Pickles Pregnancy Law 91). 
pregnancy entails a relationship between the pregnant woman and "other life forms" such as the unborn, due to the belief that all life has inherent value - the foetus is believed to be biologically alive before birth and believed to be unique. ${ }^{63}$

However, (and although prenatal life should be valued) pregnancy is a woman's concern and this special connection is to be understood as being within the framework of the prioritisation of the rights of the pregnant woman, who should have free choice to have the pregnancy terminated, especially during the first two trimesters. The interests of the foetus (the foetus is not understood to have rights) should also be taken into consideration, and here human dignity and viability play a qualifying role in awarding the foetus protection, especially during the third trimester. In this regard, Pregnancy Law presents a view of pregnancy that is sensitive to the rights of the pregnant woman and the interests of the foetus and promotes "a third relational approach" in addition to the single-entity and separateentities approaches. This "third relational approach" (or the not one/not two view) is thought to provide a remedy to what Pickles refers to as the tension between the extremes of the single-entity and separate-entities approaches. In this context, Pickles addresses the following aspects of pregnancy (as alluded to earlier): foetal personhood, violence against pregnant women that terminates pregnancies, substance abuse during pregnancy, and termination of pregnancy. ${ }^{64}$

\section{A compromise, middle ground and a third approach?}

From the above, it is clear what the predispositions underlying Pregnancy $L a w^{65}$ are. They can be briefly described as awarding the pregnant woman full discretion to decide to undergo an abortion (or, as Pickles would prefer to call it, termination of pregnancy) during the first two trimesters. ${ }^{66}$ The

63 Pickles Pregnancy Law 158 (emphasis added).

64 See Pickles Pregnancy Law 155-190.

65 As is the case with anyone who aims at coming to a finding regarding the question as to whether abortion should be legalised or not.

66 Irrespective of whether the Choice Act attaches conditions to allowing for a "termination of pregnancy" during the second trimester, it remains easy for the pregnant woman to undergo a "termination of pregnancy" during this phase (as alluded to earlier). In this regard, a decisive factor set out in the Choice Act for the granting of permission for a termination of pregnancy is whether or not "the continued pregnancy would significantly affect the social or economic circumstances" of the woman (in terms of 2(1)(b)(iv) of the said Act). Van Oosten, referring to Milton, observes that the term "social circumstances" is regarded "as wide and vague and probably relating to pregnancies resulting from adultery or a casual act of sexual intercourse with a stranger" (Van Oosten 1999 SALJ 69). According to Milton, says Van Oosten, "'economic circumstances' include an inability to afford to bring up the 
relational theory that Pickles presents (being based essentially on the scholarship of Nedelsky), which is blended with the not-one/not-two approach (which is based essentially on the scholarship of John Seymour) in the quest towards seeking "a less adversarial" understanding regarding the pregnant woman and the unborn in the contexts of pregnancy is in itself moulded by Pickles' views on how the unborn should be understood. Consequently, such views naturally permeate her critique of scholarship in support of the so-called separate-entities approach (regarding specifically, as indicated by Pickles, the South African context and related scholarship), including matters related to the extension of legal status to the unborn, violence against pregnant women; and the instance of women inflicting harm on themselves during pregnancy. ${ }^{67}$

Having said this, this appraisal primarily critiques Pregnancy Law's claims to providing a compromise, sensitivity, the attainment of a middle ground and a third approach regarding what Pickles refers to as the extremes of the single-entity and separate-entities approaches. Is Pickles indeed justified in making such claims about the relationship between the pregnant woman and the unborn when taking cognisance of the array of theories related to whether abortion should be legalised or not?

The form that any relational approach regarding the pregnant woman and the unborn is bound to take will, in the first instance, be dictated by a specific take on what an understanding of the unborn is, which is inextricably related to a view of how the unborn should be treated. Indeed, one can also argue for an understanding of "the relational", even as part of a more primary or foundational mode of argument that may precede it 68 - one that views the unborn as being human (or a person) throughout the pregnancy and deserving of protection. What of an understanding of "the relational" that has as its point of departure the belief that the unborn is a human being (or a person) from the moment of fertilisation ${ }^{69}$ and deserving of protection? ${ }^{70}$

child and the likelihood that taking the pregnancy to term would have an adverse effect upon the welfare of the family or the woman's employment opportunities" (Van Oosten 1999 SALJ 69). In fact, Pickles' critique of the South African scholarship in support of the "separateentities" approach implies a similar critique of international scholarship that is supportive of the protection of the unborn during the whole of a pregnancy. For example, an argument primarily based on scientific analysis.

69 Briefly explained, this is when the sperm cell fuses with an oocyte so as to form a zygote, the latter housing all the hereditary factors which come through the mother and father. applied to the abortion issue) that humans live fully only in a "set of relationships to certain particular others who are able to give us what we need" (Maclntyre, cited in 
This points to the variety of the possible understandings of what could be meant by "the relational". Protecting the unborn until birth, except, for example, in instances where the life of the pregnant woman is seriously at risk because of the pregnancy (or even due to the serious deformity of the unborn), may be viewed by many, including many pregnant women, as humane and respectful towards human life. Also, to those who view the unborn as being human (or a person) and worthy of protection, ${ }^{71}$ the "value of connection"72 and the "shared connection"73 that Pickles refers to can also be interpreted in a manner different from Pickles' - in other words, in a way that understands the "value of connection" and the "shared connection" as leading to the protection of the unborn throughout the whole of the pregnancy. In following such an understanding that contrasts with that of Pickles', the responsibility of protecting the unborn in so far as the pregnant woman's life is, for example, not seriously threatened in the process, is supported by those who attach such a degree of importance to the unborn to merit the protection of the unborn. Therefore, that which pertains to "the relational" regarding abortion will lead to insights that differ from those supported by Pregnancy Law, each of these insights being determined primarily by what the unborn is viewed as being.

There is an awkwardness regarding Pregnancy Law's proclamation of the attainment of sensitivity, a compromise, a middle ground and a third approach regarding the pregnant woman and the unborn, against the background of what Pickles refers to as the extremes of the single-entity and the separate-entities approaches. The question of the relevance of such phrases to the whole spectrum of differing views related to the question of whether abortion should be legalised or not (and concomitant views on the nature of the unborn) arises. In turn, given the existence of such a variety of approaches to the abortion issue (and whether it should be legalised or

Lee Abortion and Unborn Human Life 126). This relates to the understanding that, as explained by Lee, "we are beneficiaries of being members of a network of giving and receiving, and this network of giving and receiving involves duties toward those from whom we have received nothing, and with whom we have not entered any voluntary association" (Lee Abortion and Unborn Human Life 126-127). Therefore, says Lee, "I ought to help my child, and so I have special responsibilities to my child, because to help him or her is a duty I incur as part of entering that network of giving and receiving, which is constitutive of flourishing as a virtuous person" (Lee Abortion and Unborn Human Life 128).

For informative scholarship in support of this see for example Lee Abortion and Unborn Human Life; Lee and George "Wrong of Abortion" 13-26; George and Lee 2009 EMBO Reports 301-306; Perry Toward a Theory of Human Rights 52-59.

73 See Pickles Pregnancy Law 8. 
not), it is impossible to come up with an argument that will comport with all of these views. Therefore there can be no middle ground, sensitivity, compromise, or a third position to achieve across the wide spectrum of these different approaches. Pickles comments that Pregnancy Law aims at "developing a view of pregnancy in law that is sensitive to both women's rights and foetal interests ...",74 and that "the not-one/not-two approach offers a compromise in a situation that could have easily resulted in the rise of an environment for tensions during pregnancy", ${ }^{75}$ as well as that "the notone/not-two approach to pregnancy is seen to rest between the two extremes of the single-entity and the separate-entities approaches to pregnancy, offering a middle ground". ${ }^{76}$ Not all those who hold views on the status of the unborn would agree with Pregnancy Laws claims that sensitivity, a compromise and a middle ground have been attained by its argument. The same applies to Pregnancy Law's "dedication to developing sound legal concepts of pregnancy and meaningful legal responses to pregnancy-related issues"77 as well as the attainment of "the coexistence between the pregnant woman and the unborn". ${ }^{78}$ Even within Pregnancy Laws own frame of reference, it is doubted whether the reference to "sensitivity to both" is accurate, bearing in mind that Pregnancy Law's point of departure is anchored in the awarding of rights to the pregnant woman but not to the unborn, and its opposition to the view that the unborn is human or constitutive of human life (or a person) and worthy of protection throughout the whole of the pregnancy.

As alluded to in the above, specific insights, coupled with an understanding of the unborn, as well as the attendant methods and measures applied to arrive at such an understanding (such as looking through the lens of science or reproductive rights), have given rise to many works reflecting many different approaches and consequent interpretations, each with its own claims to achieving reasoned outcomes. Bearing this in mind, it would seem to be appropriate to avoid popular labels such as "pro-life" or "pro-choice" or "one-entity" or "separate-entities" or "not-one/not-two". In this regard, Robert Baird comments that labelling approaches to these issues as either "pro-life" or "pro-choice" incorrectly intimates that there are only two mutually exclusive positions to take. The same should apply to references to single-entity, separate-entities and not-one/not-two approaches in the

\footnotetext{
$74 \quad$ Pickles Pregnancy Law 289 (emphasis added).

75 Pickles Pregnancy Law 152.

76 Pickles Pregnancy Law 142 (emphasis added). Also see Pickles Pregnancy Law 152, 186-187.

77 Pickles Pregnancy Law 1-2 (emphasis added).

78 Pickles Pregnancy Law 11 (emphasis added).
} 
sense that these should not represent three mutually exclusive approaches. According to Baird, a more appropriate approach would be to "present the issue in terms of a continuum of perspectives, ranging from the radically liberal position which defends abortion for any reason and at any point in foetal development to the radically conservative view which opposes abortion under any circumstances, even to save the life of the mother". ${ }^{79}$ More specifically, this continuum of perspectives has to do with perceptions/convictions/beliefs inextricably related to an understanding of the nature of the unborn (whether regarding specific phases of the biological development of the unborn or to the duration of pregnancy as a whole), which in turn feeds into the reasoning for approaching the unborn in a specified fashion. Even Pickles' understanding of what should be understood regarding the separate-entities approach is open to different meanings. 80

Lee points to gradualist theories related to the abortion issue and explains that these theories share the understanding that there are varying degrees of moral standing during pregnancy in that embryos during the early stage lack moral standing, whilst older embryos (or younger foetuses) have partial moral standing and older foetuses bear a moral standing that is similar to that of infants. According to Lee, these theories are viewed by the propagators thereof as providing "a golden mean between the extremes of

79 Baird 1995 J Church \& State 754. This is aligned with Tom Stacy's comment that "One suspects that many conservatives do not ultimately believe that an early fetus has the full right to life of a newborn infant or an adult. They are uncomfortable not only with the radical tactics of some in the pro-life movement, but also with the extremism of much pro-life rhetoric itself. Likewise, many liberals probably do believe that insensate early fetal life, although lacking the moral value necessary to ground a right to life, still has a very high moral value" (Stacy 1994 Geo Wash L Rev 15). Pickles describes this approach as supporting the ideas for example of "separate status and enforceable rights" (Pickles Pregnancy Law 144); "separate individuals of distinctive value and needs" (Pickles Pregnancy Law 158); and "tends to have followers from the pro-life" approach (Pickles Pregnancy Law 7). What of a separateentities approach that supports "a separate status" but does not agree that rights should be enforced on the part of the unborn? What of a view that understands viability as the point of introducing a separate status and enforceable rights and therefore as a golden mean so as to balance the rights of the pregnant woman and that of the foetus? What exactly is meant by the "pro-life" approach? Surely there are a multitude of different approaches within the pro-life camp itself? All these confirm that Pickles' proposed separate-entities approach references only one aspect of what a separate-entities approach should be understood to be, thereby placing the plotting of the separate-entities approach in a multitude of possible places on the continuum of pregnancy. This also calls into question Pickles' claim of having provided a third approach (in addition to that of the single-entity and separateentities approaches). 
the conservative and the liberal positions regarding abortion". ${ }^{81}$ As an example of this, Lee refers to Sumner's proposed "third way", which applies sentience $^{82}$ as a criterion to determine the moral standing within the more significant gradualist approach (referred to earlier). ${ }^{83}$ In using the sentience criterion, Sumner postulates that the embryo has no moral standing during the first trimester due to the embryo being present. However, this organism, says Sumner, begins to acquire moral standing in the second trimester, and in the third trimester, the moral standing of the foetus is the same as that of the infant at birth. ${ }^{84}$ Similarly, the "third approach" argued for in Pregnancy Law and its aim of presenting a "golden mean between the extremes of the conservative and the liberal positions regarding abortion" is also reflective of one of the many gradualist theories, Sumner's being another example. Just as sentience serves as a criterion for Sumner's argument, so does Pickles' emphasis on viability and human dignity against the background of a specific relational understanding serve as a criterion to be applied to the abortion matter in the context of the gradualist approach. Also, as Lee rightly points out regarding Sumner's gradualist approach (and this of relevance to Pregnancy Law as well)

The rhetorical appeal of this approach should not be underestimated. Any position which can be presented as taking a virtuous mean, especially on a highly controversial issue, has tremendous appeal. People naturally fear outright confrontation and so a moderate position - which allows one to say that one partly agrees with each side without, of course, their alleged peculiar exaggerations - has significant appeal..$^{85}$

Similarly, Pregnancy Law may initially seem appealing as a result of what may be perceived as its providing "a golden mean between the extremes of the conservative and the liberal positions" in its opposition to the singleentity and separate-entities approaches as well as in its claiming to be sensitive and to promote compromise, a middle ground and a third approach (against the background of what Pickles refers to as the extremes of the single-entity and separate-entities approaches). From what was said earlier, it is evident that there is a wide spectrum of approaches regarding when an

$81 \quad$ Lee Abortion and Unborn Human Life 47-48.

82 Although open to many layered views, in simplistic terms it denotes some or other degree of mental activity which overlaps with the capacity to experience, feel or perceive or the capacity for some or other feeling or effect on the part of the unborn. Lee Abortion and Unborn Human Life 48.

$84 \quad$ Lee Abortion and Unborn Human Life 50.

85 Lee Abortion and Unborn Human Life 50. This also pertains to efforts at synthesis in the sense of attempting to somehow accomplish the co-ordination of contrasting positions, and the failure to admit that such synthesis constitutes just another particular standpoint amongst all the other standpoints on a given matter. In this regard, see Rescher Pluralism 94. 
abortion should be granted (and possibly even the extreme approach in support of an absolute prohibition of abortion) which relate to the variety of meanings imputed to the unborn, which in turn are related to a continuum of views ranging from the extreme position that defends abortion for any reason and during any time of the pregnancy (as long as the pregnant woman's health is not seriously threatened by having to go for an abortion) to the extreme view that opposes abortion under any circumstances, even to save the life of the mother or where there is a serious deformity of the unborn). This, in turn, makes it questionable to aver that a specific approach in this regard constitutes an encompassing category, as in the case of Pregnancy Law's claim that it presents a third category that essentially deals with "the relational". "The relational" itself is open to the possibilities of different approaches related to the continuum between the extreme approaches, as explained earlier.

It is reiterated that Pickles' claim that Pregnancy Law "establishes a third, ${ }^{86}$ relational approach to taking foetal interests into account ..." 87 and her belief that "[t]hree approaches to pregnancy exist: the single-entity, the separateentities and the not-one/not-two approaches" 88 is a matter of concern. ${ }^{89}$ The picture sketched by Pickles in this regard is that Pregnancy Law constitutes a third primary approach in addition to the single-entity and the separateentities approaches. However, this is far from being the case in that Pregnancy Law constitutes one of many examples of approaches towards the abortion issue and, by implication, understandings of the unborn. Pickles' relational theory and her proposed not-one/not-two approach are outcomes of her view on the unborn during the various stages of pregnancy, which in turn is only one of many possible understandings of the nature of the unborn (and consequently of whether the unborn should be protected). For argument's sake, and based on a relational understanding, why not instead label as a possible third relational approach the view that the defining moment from which the unborn should be protected should be at the end of eight weeks post conception? According to Donal Hope, it is at this stage that the hand of the unborn emerges and that electrical activity

\footnotetext{
86 In addition to the single-entity approach as well as the separate-entities approach.

87 Pickles Pregnancy Law 10-11 (emphasis added).

88 Pickles Pregnancy Law 343.

89 Pickles Pregnancy Law 344 (emphasis added). What Pickles is also saying here in effect also relates to legal systems beyond South Africa where approaches to the abortion issue have been confined to what Pickles refers to as the single-entity and separate-entities approaches.
} 
that is measurable by EEG first begins to show in the brain of the unborn. ${ }^{90}$ What makes Pickles' approach preferable as a third approach to that of Donald Hope's?

\section{Conclusion and related remarks}

After having pointed to the essentials of Pregnancy Law in the context of abortion, clarification has been provided regarding the foundations on which Pregnancy Law rests. Consequently, it has been confirmed that Pregnancy Law places the legal protection of the unborn in a secondary position when compared with the pregnant woman and the rights awarded to her. Pregnancy Law (irrespective of the formula applied) offers a result that is supportive of the unrestrained freedom of the pregnant woman to choose, during the first two trimesters, to have her "pregnancy terminated". This is also to be understood in the context of Pregnancy Law's rejection of the view that the unborn is human (or a person) and deserving of protection throughout the pregnancy.

Pregnancy Law takes but one of a plethora of views on the nature of the unborn (and the accompanying action to be taken). Therefore there should be no particular reason that others, whose moral (and scientific) views differ from it, should find Pregnancy Law persuasive. This is especially worthy of note, bearing in mind Pickles' claim that there was, before the publication of Pregnancy Law, a lack of an informed foundation for the South African context from which to work, and that Pregnancy Law introduces the correct approach. This also relates to Pregnancy Law's questionable dedication to developing sound legal concepts of pregnancy and meaningful legal responses to pregnancy-related issues, and to finding a middle ground, a compromise, sensitivity and a third approach to the matter in the context of what Pickles refers to as the extremes of the single-entity and separateentities approaches. The relational approach that Pregnancy Law postulates is in itself moulded by a specific understanding of the unborn. In this regard, other possible differing views on how the relational should be understood against the background of viewing the unborn as worthy of protection throughout the pregnancy should not be excluded. This, in turn, gives rise to concern regarding Pregnancy Law's claim that the not-one/nottwo approach establishes a third relational approach in addition to that of the single-entity and the separate-entities approaches.

90 For more on this as the defining moment regarding the protection of the unborn see Hope 2001 U Tol L Rev 205-228. 
The not-one/not-two approach is but one of many views on the continuum between the belief in the unfettered freedom of the pregnant woman to undergo an abortion and the extreme view that abortion should be prohibited in all instances. The not-one/not-two approach is but one of the wide spectrum of theories directed at the subject of abortion and whether it should be legalised or not and if so, to what degree. Bearing this in mind, the inclusion of Pregnancy Law in the records of abortion jurisprudence related to the South African context must be accompanied by the following comment by Carter, in his review of Laurence H Tribe's Abortion: The Clash of Absolutes, which is based upon what Carter refers to as a pro-choice platform:91 "The choice that he [Tribe] makes is moral and principled and might even be the one that most people in our society would prefer, at least as a matter of law ... but there is no particular reason that others, whose moral starting points are very different from Tribe's, should find his argument persuasive ...".92

Similar to Carter's critique of Tribe's take on abortion, there should be no particular reason why others, whose moral points of departure are different from those of Pickles', should find Pregnancy Law persuasive, and nor should Pregnancy Law be perceived as the ultimate authority regarding jurisprudence on abortion in South Africa. There is no doubt that Pregnancy Law will interest jurists and law students engaged in debate related to abortion, both in South Africa and beyond, amongst others. It is therefore imperative to expose the foundational claims on Pregnancy Law's take on the nature of the unborn, with a special focus on abortion, but which also has implications for the discussion of other themes that Pregnancy Law addresses, such as foetal personhood, violence against pregnant women that terminates pregnancies, and substance abuse during pregnancy.

Although also aiming at benefitting a woman who decides to continue with her pregnancy, Pregnancy Law's staunch support of an argument that is based on the view that the unborn is not human and deserving of protection throughout pregnancy may be challenging for the pregnant woman who staunchly believes that the unborn is human and worthy of protection. Smolin refers to the unfortunate probability that

the success of the abortion rights movement has created a situation where some pro-life women have embraced the sexist presumption that a woman must choose between her equality and future life on one hand, and her conscience and the life of her unborn child on the other hand. This set of

$91 \quad$ Carter 1991 Yale LJ.

92 Carter 1991 Yale LJ 2763. 
presumptions places pro-life women in a box under which they lose regardless of which choice they make. ${ }^{93}$

Smolin adds that, regarding the position in the US (only a couple of years ago), ${ }^{94}$ a substantive number of women self-identify as pro-life ${ }^{95}$ and comments that

This tendency to dismiss as irrelevant the views of the majority of women who either identify as pro-life, or who remain in the ambivalent middle on abortion, illustrates the profound disrespect of the abortion rights movement toward women. Since some anti-abortion women purportedly speak by their actions of undergoing abortions, the views and words of all anti-abortion women are disregarded. Anti-abortion women are dismissed as hypocritical, inconsistent, and naïve, and influenced by anti-abortion 'propaganda,' and rigid religious teaching. By such reasoning the abortion rights movement tends to dismiss as irrelevant women's moral reasoning on abortion. ${ }^{96}$

This is also of relevance when taking into cognisance Pickles' sweeping comment that her proposed not-one/not-two approach constitutes "a female view of pregnancy". ${ }^{97}$ Even though Pregnancy Law supports the choice that the pregnant woman should have to continue with the pregnancy up until birth, Pregnancy Law's substantive emphasis on the importance of the pregnant woman's free choice to undergo an abortion ${ }^{98}$ may result in a situation where a woman that views the unborn within her as human experiences substantive discomfort as a result of being pressured from sources representing contrasting poles related to an understanding of the unborn. ${ }^{99}$ Closely related to this concern is the psychological impact that an

Smolin 2018 UC Irvine L Rev 698-699. Smolin refers to pro-life feminist Callahan's comment, "Pitting women against their own offspring is not only morally offensive, it is psychologically and politically destructive. Women will never climb to equality and social empowerment over mounds of dead fetuses ... As long as most women choose to bear children, they stand to gain from the same constellation of attitudes and institutions that will also protect the fetus in the woman's womb - and they stand to lose from the cultural assumptions that support permissive abortion" (Smolin 2018 UC Irvine L Rev 698-699).

Surely there are many other countries where this is also the case. Smolin 2018 UC Irvine L Rev 702-703. Smolin 2018 UC Irvine L Rev 704.

Pickles Pregnancy Law 142.

98 Which is similar to any other approach or theory that results in the pregnant woman having substantive freedom to choose to undergo an abortion.

99 Talking of discomfort, how should the following scenario play out if the approach proposed in Pickles Pregnancy Law is adopted? "A couple wants a child very much. They would particularly like to have a boy. The wife becomes pregnant, and because she is thirty-five, she is advised to have amniocentesis. The results show that the fetus appears to be perfectly healthy and that it is female. She now wants to have an abortion and try again in a few months to have a boy. Is it morally permissible for her to have an abortion?" Anderson 1987 PAQ 89. 
abortion may have on the woman who experienced it - a condition referred to as a post-abortion syndrome. ${ }^{100}$ This adds to the importance of being sensitive to the rights of pregnant women in the context of the protection of the unborn. Lee comments that although it is difficult to say what percentage of women experience post-abortion syndrome, there are several factors that suggest the widespread nature of the said syndrome. In this regard, Lee refers to the likelihood that many women do not come into the open about this due to the possible shame that may be involved. ${ }^{101}$

Then there is the possibility of the hiding of guilt even from those who underwent abortions themselves. In addition, "sometimes even intense activism in the pro-abortion cause have often been cited by women who later regret their abortions as ways of trying to avoid facing up to the problem". ${ }^{102}$ Lee also points to the establishment of a multitude of support groups established to assist women that suffer from the post-abortion syndrome, which also confirms the widespread nature of the post-abortion syndrome. ${ }^{103}$ Bearing the above in mind, the reader of Pregnancy Law should be reminded of those pregnant women who are supportive of the understanding that the unborn should enjoy protection throughout the pregnancy and should not ignore the dire consequences ${ }^{104}$ that can ensue for a woman who has undergone an abortion.

As stated at the outset, the questions of the nature of the unborn and whether the unborn should be protected or not have attracted diverse answers over a lengthy period from prominent scholars, amongst others. Having said this, the importance of the matter at hand, namely the determination of the parameters related to the commencement of human life and the consequent legal protection thereof, necessitates a continuation of the debate, irrespective of differences, emotions and complexities involved, and even if it means having to be critical (and even robustly critical at times) of the views of others on such a fundamental matter. Engaging in such criticism is a mark of respect to those who engage in debate about the commencement of human life and the concomitant freedom to deliberate on a matter of such moral importance. It is in this context that this appraisal

100 See Lee Abortion and Unborn Life 161-163. There is scholarship that questions the existence of this condition (post-abortion syndrome) although post-abortion grief is accepted as something real. See Manninen 2013 Hypatia 673-674. It is surely insensitive to suggest that grief should be taken lightly.

101 Lee Abortion and the Unborn Life 163.

102 Lee Abortion and the Unborn Life 163.

103 Lee Abortion and the Unborn Life 163.

104 Irrespective of whether or not the condition referred to as "post-abortion syndrome" exists (supra). 
should be understood, also bearing in mind Carter's comment that "[c]riticism is the beginning of dialogue, and, in a vibrant democracy, dialogue is what citizens do". ${ }^{105}$ There was critical dialogue regarding the legalisation of abortion long before the publication of Pregnancy Law, and Pregnancy Law itself is an example of critical dialogue. This appraisal will also undoubtedly be followed by further critical dialogue on the said topic, which is to be expected not only in a democracy but also in that area of jurisprudence that busies itself with the commencement of being human.

\section{Bibliography}

\section{Literature}

Anderson 1987 PAQ

Anderson SL "Criticisms of Liberal/Feminist Views on Abortion" 1987 PAQ 83-96

\section{Baird 1995 J Church \& State}

Baird RM "Abortion, Religious Liberty, and the Spirit of Enlightenment" 1995 J Church \& State 753-771

Beckwith and Geisler Matters of Life and Death

Beckwith FJ and Geisler NL Matters of Life and Death: Calm Answers to Tough Questions About Abortion and Euthanasia (Baker Book House Grand Rapids, Michigan 1991)

\section{Bork Tempting of America}

Bork RH The Tempting of America. The Political Seduction of the Law (Touchstone New York 1990)

\section{Bradley 2014 Notre Dame L Rev}

Bradley GV "Life's Dominion: A Review Essay" 2014 Notre Dame L Rev 329-391

\section{Buelow 1998 Temp L Rev}

Buelow III WE "To Be and Not to Be: Inconsistencies in the Law Regarding the Legal Status of the Unborn Foetus" 1998 Temp L Rev 963-994

$105 \quad$ Carter Civility 211. 
Byrn 1973 Fordham L Rev

Byrn RM "An American Tragedy: The Supreme Court on Abortion" 1973 Fordham L Rev 807-862

Carter 1991 Yale LJ

Carter SL "Abortion, Absolutism, and Compromise (Book Review of Laurence H Tribe's Abortion: The Clash of Absolutes)" 1991 Yale LJ 27472766

Carter Civility

Carter SL Civility: Manners, Morals, and the Etiquette of Democracy (Basic Books New York 1998)

De Freitas 2005 JJS

De Freitas SA "A Critical Retrospection Regarding the Legality of Abortion in South Africa" 2005 JJS 118-145

Dworkin Life's Dominion

Dworkin R Life's Dominion: An Argument About Abortion and Euthanasia (HarperCollins London 1993)

Ely 1973 Yale LJ

Ely JH "The Wages of Crying Wolf: A Comment on Roe v Wade" 1973 Yale LJ 920-949

Frankowski "United States of America"

Frankowski SJ "United States of America" in Frankowski SJ and Cole GF (eds) Abortion and Protection of the Human Fetus: Legal Problems in a Cross-Cultural Perspective (Martinus Nijhoff Dordrecht 1987) 17-74

George "State Legislatures Versus the Supreme Court"

George B "State Legislatures Versus the Supreme Court: Abortion Legislation Into the 1990s" in Butler JD and Walbert DF Abortion, Medicine, and the Law $4^{\text {th }}$ ed (Facts on File New York 1992) 3-77

George and Lee 2009 EMBO Reports

George RP and Lee P "Embryonic Human Persons" 2009 EMBO Reports 301-306

Haley 1974 Suffolk $U L$ Rev

Haley JN "Haunting Shadows from the Rubble of Roe's Right of Privacy" 1974 Suffolk U L Rev 145-184 
Hope 2001 U Tol L Rev

Hope D "The Hand as Emblem of Human Identity: A Solution to the Abortion Controversy Based on Science and Reason" 2001 U Tol L Rev 205-228

Horan and Balch "Roe $v$ Wade"

Horan DJ and Balch TJ "Roe $v$ Wade: No Justification in History, Law, or Logic" in Horan DJ, Grant ER and Cunningham PC (eds) Abortion and the Constitution: Reversing Roe $v$ Wade Through the Courts (Georgetown University Press Washington DC 1987) 57-88

Lee Abortion and Unborn Human Life

Lee P Abortion and Unborn Human Life $2^{\text {nd }}$ ed (The Catholic University of America Press Washington DC 2010)

Lee and George "Wrong of Abortion"

Lee P and George RP "The Wrong of Abortion" in Cohen Al and Wellman $\mathrm{CH}$ (eds) Contemporary Debates in Applied Ethics (Wiley-Blackwell Oxford 2005) 13-26

Manninen 2013 Hypatia

Manninen BA "The Value of Choice and the Choice to Value: Expanding the Discussion About Fetal Life Within Prochoice Advocacy" 2013 Hypatia 663683

O'Meara 1974 Sup Ct Rev

O'Meara J "Abortion: The Court Decides a Non-Case" 1974 Sup Ct Rev 337-360

Nedelsky 1989 Yale J L \& Feminism

Nedelsky J "Reconceiving Autonomy: Sources, Thoughts and Responsibilities" 1989 Yale J L \& Feminism 7-36

Nedelsky 1993 CJLJ

Nedelsky J "Property in Potential Life? A Relational Approach to Choosing Legal Categories" 1993 CJLJ 343-365

Nedelsky Law's Relations

Nedelsky J Law's Relations: A Relational Theory of Self, Autonomy, and Law (Oxford University Press Oxford 2013)

Ngwena 1998 Acta Academica

Ngwena C "The History and Transformation of Abortion Law in South Africa" 1998 Acta Academica 32-68 
Ngwena 2000 JJS

Ngwena C "Accessing Abortion Services Under the Choice on Termination of Pregnancy Act: Realising Substantive Equality" 2000 JJS 19-42

Ngwena 2004 JLME

Ngwena C "An Appraisal of ABORTION LAWS in Southern Africa from a Reproductive Health Perspective" 2004 JLME 708-717

Paulsen 2003 Notre Dame L Rev

Paulsen MS "The Worst Constitutional Decision of All Time" 2003 Notre Dame L Rev 995-1044

Perry Toward a Theory of Human Rights

Perry MJ Toward a Theory of Human Rights: Religion, Law, Courts (Cambridge University Press Cambridge 2007)

Pickles Pregnancy Law

Pickles C Pregnancy Law in South Africa: Between Reproductive Autonomy and Foetal Interests (Juta Cape Town 2017)

Pillay 2010 Stell LR

Pillay $R$ "The Beginning of Human Personhood: Is South African Law Outdated?" 2010 Stell LR 230-238

Rescher Pluralism

Rescher N Pluralism. Against the Demand for Consensus (Clarendon Press Oxford 1993)

Rice 1973 Boston Coll Int'l \& Comp L Rev

Rice CE "Overruling Roe $v$ Wade: An Analysis of the Proposed Constitutional Amendments" 1973 Boston Coll Int'l \& Comp L Rev 307-341

Seymour Childbirth and the Law

Seymour J Childbirth and the Law (Oxford University Press Oxford 2000)

Smith 1983 Jurist

Smith PA "The Right to Privacy: Roe $v$ Wade Revisited" 1983 The Jurist 289-317

Smolin 2018 UC Irvine L Rev

Smolin DM "Aborting Reason and Equality: A Religious Pro-Life Critique of Roe, Casey, and Abortion Rights Rhetoric" 2018 UC Irvine L Rev 673-709 
Stacy 1994 Geo Wash L Rev

Stacy $T$ "Reconciling Reason and Religion: On Dworkin and Religious Freedom" 1994 Geo Wash L Rev 1-75

Steegmann 1987 Ind LJ

Steegmann EP "Of History and Due Process" 1987 Ind LJ 369-399

Van Oosten 1999 SALJ

Van Oosten $F$ "The Choice on Termination of Pregnancy Act: Some Comments" 1999 SALJ 60-76

Witherspoon 1985 St Mary's LJ

Witherspoon JS "Reexamining Roe: Nineteenth-Century Abortion Statutes and the Fourteenth Amendment" 1985 St Mary's LJ 29-77

\section{Case law}

Roe $v$ Wade 410 US 113 (1973)

Doe v Bolton 410 US 179 (1973)

\section{Legislation}

Choice on Termination of Pregnancy Act 92 of 1996

\section{List of Abbreviations}

Boston Coll Int'l \& Comp

L Rev

CJLJ

EMBO Reports

Fordham L Rev

Geo Wash L Rev

Ind LJ

J Church \& State

JJS

JLME

Notre Dame L Rev

$P A Q$

SALJ

St Mary's LJ

Stell LR
Boston College Industrial and Commercial Law Review

Canadian Journal of Law and Jurisprudence European Molecular Biology Organisation Reports

Fordham Law Review

George Washington Law Review

Indiana Law Journal

Journal of Church and State

Journal for Juridical Science

Journal of Law, Medicine and Ethics

Notre Dame Law Review

Public Affairs Quarterly

South African Law Journal

St Mary's Law Journal

Stellenbosch Law Review 
Suffolk U L Rev

Temp L Rev

Sup Ct Rev

UC Irvine L Rev

U Tol L Rev

Yale J L \& Feminism

Yale LJ
Suffolk University Law Review

Temple Law Review

The Supreme Court Review

UC Irvine Law Review

University of Toledo Law Review

Yale Journal of Law and Feminism

Yale Law Journal 